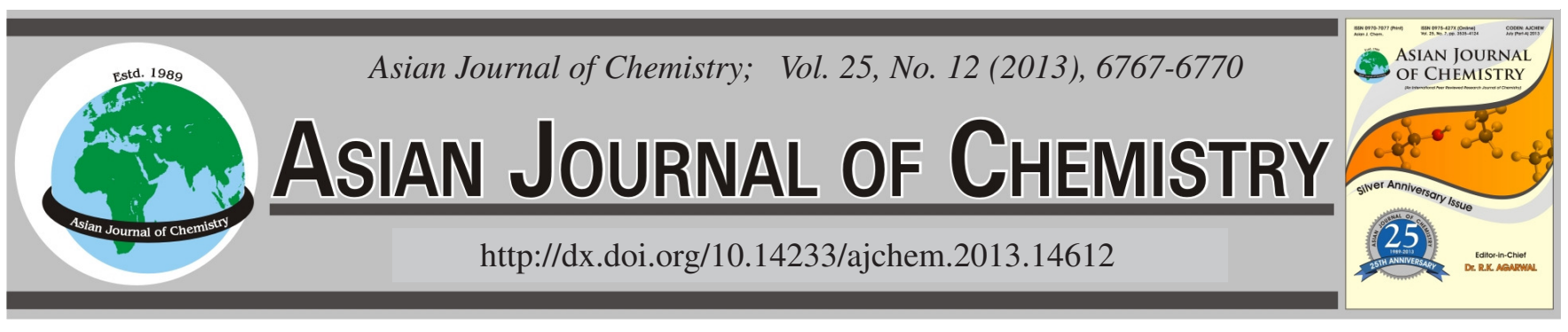

\title{
Sol-Gel Synthesis and Spectroscopic Analysis of Chromium in Sol Gel Silica
}

\author{
Jeena Thomas ${ }^{1}$, AJith Verghese George ${ }^{1}$ and Vinoy Thomas ${ }^{2, *}$
}

${ }^{1}$ Department of Chemistry, Mar Ivanios College, Thiruvananthapuram-695 015, India

${ }^{2}$ Department of Physics, Christian College, Chengannur-689 122, India

*Corresponding author: Fax: +91 479 2450375; E-mail: vinoythoma@ gmail.com

(Received: 25 September 2012;

Accepted: 31 May 2013)

AJC-13567

Dense chromia-silica glasses have been successfully synthesized by the sol-gel method. Optical absorption and electron spin resonance studies are used to get the insight information about the prepared matrices. As the heat treatment temperature increased, $\mathrm{Cr}^{3+} \rightarrow \mathrm{Cr}^{6+}$ conversion was facilitated, thereby generating $\mathrm{Cr}^{5+}$ ions in the matrix. The amount of $\mathrm{Cr}^{5+}$ and $\mathrm{Cr}^{6+}$ centers can vary depending on the preparation conditions. Racaah parameter (B) of chromium in the octahydral symmetry has been evaluated by using the spectral data. The reduction of Racaah parameter from its free ion value $\left(918 \mathrm{~cm}^{-1}\right)$ reflects the presence of covalent bonding in the matrix. An attempt has been made to explain the nature of chromium on the basis of rule of ratio of radius.

Key Words: Sol gel process, Optical materials, Electron spin resonance, Crystal field parameters.

\section{INTRODUCTION}

At present time there is a rising demand for new materials to be used for device fabrication in optical communications and photonics technology. They must meet stringent requirements of composition, purity and microstructural properties, which demand sophisticated processing. Advanced materials processing must lead to optimal properties such as fine particles, controlled chemistry, homogeneity etc. Recent research reports show a large-scale utilization of chemical processing techniques to produce such high performance materials. Sol-gel methods are extensively used for the preparation of optical materials by incorporating different cations or molecules in a silica host $\mathrm{t}^{1,2}$. First row transition metal ions $\mathrm{s}^{3,4}$ and rare earth ions $^{5,6}$ have been utilized for this purpose. It was found that during the gelation process metal ion can occupy different valencies. The hydrolysis reaction creates the extreme chemical conditions leading to the changes of metal ion charges. Different valencies have been observed for lanthanides like $\mathrm{Ce}^{7}$ and Pr ions in silica sol-gel glasses ${ }^{8}$.

Chromium has long been used as a colouring agent in glass, but the limited solubility of chromium oxide in glasses restricts its applications ${ }^{9}$. The chromium ion is likely to play an important part in the development of new solid state laser materials because of its favourable absorption and emission properties ${ }^{10}$. It is well known that the first laser in history was made of ruby, of which the lasing ion is $\mathrm{Cr}^{3+11}$. The first solid state tunable ionic laser, the Alexandrite laser is also activated with $\mathrm{Cr}^{3+12}$. It was also found that $\mathrm{Cr}^{4+}$ is an excellent lasing ion in the near infrared ${ }^{13}$. Various types of $\mathrm{Cr}^{4+}$ lasers have been developed ${ }^{14}$. More recently $\mathrm{Cr}^{2+}$ was found to lase when doped into CdSe crystals ${ }^{15}$. Due to these reasons the study of optical properties of crystals and glasses containing chromium has received a new impulse connected both to the exploitation of these materials as active media for infrared tunable laser, luminescent solar concentrators and to the fundamental understanding of the interaction between impurity and host lattice ${ }^{16-18}$. Properties of the doped silica systems depend on the local structure and bonding of the dopant cations ${ }^{19}$, a detailed understanding of the local structure of the glass is very important to fabricate material for optical applications. In this communication, an attempt has been made to study the variations in the coordination state and the valence state of chromium during sol-to-gel and the gel-to-glass transformations.

\section{EXPERIMENTAL}

Silica sols containing 0.1 equivalent mol $\% \mathrm{Cr}_{2} \mathrm{O}_{3}$ were prepared from tetraethylorthosilicate (TEOS) (Fluka purum grade), $\mathrm{Cr}\left(\mathrm{NO}_{3}\right)_{3} .9 \mathrm{H}_{2} \mathrm{O}$ (Merck), doubly distilled deionized water and high purity $\mathrm{HNO}_{3}$ and $\mathrm{NH}_{4} \mathrm{OH}$. The desired amount of $\mathrm{Cr}\left(\mathrm{NO}_{3}\right)_{3} .9 \mathrm{H}_{2} \mathrm{O}$ dissolved in deionized water in the presence of $\mathrm{HNO}_{3}$ was poured in TEOS under stirring at room temperature. The TEOS/ $\mathrm{H}_{2} \mathrm{O} / \mathrm{HNO}_{3}$ molar ratio was $1: 14: 0.01$. The $\mathrm{pH}$ of the sols was adjusted to a value of 3 by adding $\mathrm{NH}_{4} \mathrm{OH}$. The sols were cast in petri dishes. The gels were aged for 
one week at room temperature. Transparent crack free dried monolithic gels were obtained after drying for 14 days in air oven at $60 \pm 2{ }^{\circ} \mathrm{C}$. The gels were heated at different temperatures ranging from $200-900^{\circ} \mathrm{C}$ in a programmable furnace with the rate of $3{ }^{\circ} \mathrm{C} / \mathrm{h}$. Transparent crack free and bubble free gels (diameter 30-35 mm, thickness 2-2.5 mm) were reproducibly obtained. Optical spectra of the gels and heat treated samples were recorded with UV-visible spectrophotometer (ShimadzuUVPC 2401). Room temperature ESR spectra were obtained by a Varian model E-109C spectrometer. Densities of the samples were measured by means of Archimedes principle.

\section{RESULTS AND DISCUSSION}

Optical absorption studies: The optical absorption spectra of the gel and the heat-treated specimens are shown in Fig. 1. The visible absorption bands observed in the spectra of the $60{ }^{\circ} \mathrm{C}$ dried gels are due to the octahedraly coordinated $\mathrm{Cr}^{3+}$. The absorption bands at $380-420 \mathrm{~nm}$ and $570-600 \mathrm{~nm}$ are attributed to ${ }^{4} \mathrm{~A}_{2} \rightarrow{ }^{4} \mathrm{~T}_{1}$ and ${ }^{4} \mathrm{~A}_{2} \rightarrow{ }^{4} \mathrm{~T}_{2}$ transitions respectively ${ }^{10}$. The bands were shifted towards the shorter wavelengths compared to those of the $\left[\mathrm{Cr}\left(\mathrm{H}_{2} \mathrm{O}\right)_{6}\right]^{3+}$ and $\mathrm{Cr}$ doped silica gels ${ }^{4}$. A significant decrease in the $10 \mathrm{Dq}$ value $(580 \mathrm{~nm})$ was observed indicating a decrease in the ligand field strength. It is inferred that silanol groups in siloxane oligomers formed in the sol can coordinate with $\mathrm{Cr}^{3+}$ ions along with $\mathrm{H}_{2} \mathrm{O}$ and $\mathrm{NO}_{3}{ }^{-}$. However the size of the oligomers is so large that they cannot approach the $\mathrm{Cr}^{3+}$ ion very closely leading to less overlap between the $3 \mathrm{~d}$ orbitals of the $\mathrm{Cr}^{3+}$ ion and the $2 p$ orbitals of the oxygen atoms in the silanol. Consequently the $10 \mathrm{Dq}$ value of the $\mathrm{Cr}^{3+}$ ion in the silanol becomes relatively small. Only $\mathrm{Cr}^{3+}$ and no $\mathrm{Cr}^{6+}$ (ca. $345 \mathrm{~nm}$ ) bands were observed for the gels.

The gels were heat treated to $900^{\circ} \mathrm{C}$. With increase in the temperature two features were observed in: (i) increase in UV absorption with a shift of the absorption edge towards longer wavelengths (the higher the concentration, the greater the shift), (ii) a progressive disappearance of the band at $580 \mathrm{~nm}$ and a consequent increase in the red transmission. These two features are explained in the following discussion.

In the gel, siloxane network or $\mathrm{SiO}_{2}$ colloidal particle connected with each other which cannot coordinate $\mathrm{Cr}^{3+}$ any longer because of their too big size, leaving $\mathrm{Cr}^{3+}$ ions, $\mathrm{H}_{2} \mathrm{O}$ and $\mathrm{NO}_{3}^{-}$ions in the pores. The $\mathrm{Cr}^{3+}$ ions are not incorporated into the skeleton consisting of $\mathrm{SiO}_{4}$ tetrahedra in the gel but again present as $\left[\mathrm{Cr}\left(\mathrm{H}_{2} \mathrm{O}\right)_{y}\left(\mathrm{NO}_{3}\right)_{6-\mathrm{y}}\right]^{(\mathrm{y}-3)+}$ complex. As the densification of the gel proceeds, a condensation reaction between the silica gel particles takes place. This reaction shrinks the bulk gel and may yield some compressive stress at the $\left[\mathrm{Cr}\left(\mathrm{H}_{2} \mathrm{O}\right)_{y}\left(\mathrm{NO}_{3}\right)_{6-\mathrm{y}}\right]^{(\mathrm{y}-3)}$ complex. Subsequently the $\mathrm{Cr}-\mathrm{O}$ bond is forced to shorten compared to the $\left[\mathrm{Cr}\left(\mathrm{H}_{2} \mathrm{O}\right)_{6}\right]^{3+}$ complex. As a result the interaction between the orbitals of the $\mathrm{Cr}^{3+}$ ion and the orbitals of the ligand becomes large leading to the increase in the UV absorption with a shift of the absorption edge towards longer wavelengths. As the heat treatment temperature is increased the $\left[\mathrm{Cr}\left(\mathrm{H}_{2} \mathrm{O}\right)_{y}\left(\mathrm{NO}_{3}\right)_{6-\mathrm{y}}\right]^{(\mathrm{y}-3)+}$ complex reacts with the silica gel to release $\mathrm{H}_{2} \mathrm{O}$ and $\mathrm{NO}_{3}{ }^{-}$ions and $\mathrm{Cr}^{3+}$ ions are incorporated into the silica network. In other words, the environment of $\mathrm{Cr}^{3+}$ ions approaches (Table-1) that in the sodalime silica glasses $\left(10 \mathrm{Dq}=15250 \mathrm{~cm}^{-1}\right)^{20}$ or fused silica $\left(10 \mathrm{Dq}=16000 \mathrm{~cm}^{-1}\right)^{17}$.
TABLE-1

VALUES OF 10Dq FOR DIFFERENTIAL ENVIRONMENTS

\begin{tabular}{lc} 
Specimen & $10 \mathrm{Dq}\left(\mathrm{cm}^{-1}\right)$ \\
Ethanol solution & 17200 \\
Sol & 16800 \\
Gel & 17600 \\
Fused silica & 16000 \\
Soda lime silica & 15250 \\
\hline
\end{tabular}

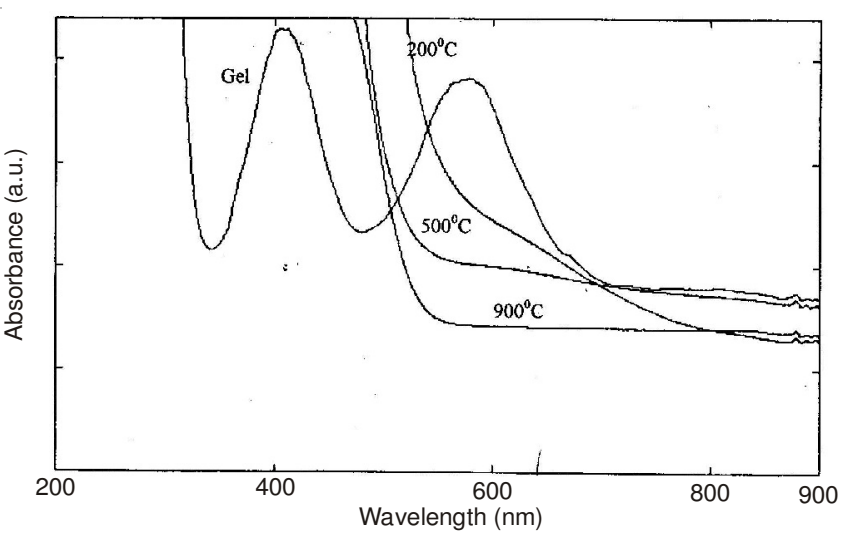

Fig. 1. Absorption spectrum of the gel and heat-treated specimen

Crystal field parameters: From the absorption and excitation measurements, using the Tanabe-Sugano model a complete level scheme of chromium in the gel host was obtained. A direct indication of the value of the local field Dq can be derived from the average peak energy of the ${ }^{4} \mathrm{~A}_{2} \rightarrow{ }^{4} \mathrm{~T}_{2}$ transition

$$
\mathrm{Dq}=\frac{\mathrm{E}_{\mathrm{a}}\left({ }^{4} \mathrm{~T}_{2}\right)-\mathrm{E}_{\mathrm{b}}\left({ }^{4} \mathrm{~A}_{2}\right)}{10}=213.14 \mathrm{meV}
$$

More over from the average peak energies of the ${ }^{4} \mathrm{~A}_{2} \rightarrow{ }^{4} \mathrm{~T}_{2}$ and ${ }^{4} \mathrm{~A}_{2} \rightarrow{ }^{4} \mathrm{~T}_{1}$ transitions the Racaah parameter $\mathrm{B}$ can be evaluated $^{21}$. Indeed B and Dq are related through the equation:

$$
\frac{\mathrm{Dq}}{\mathrm{B}}=\frac{15(\mathrm{x}-8)}{\mathrm{x}^{2}-10 \mathrm{x}}
$$

Where the parameter $\mathrm{x}$ is defined by the following equation:

$$
\mathrm{x}=\frac{\mathrm{E}_{\mathrm{a}}\left({ }^{4} \mathrm{~T}_{1}\right)-\mathrm{E}_{\mathrm{a}}\left({ }^{4} \mathrm{~T}_{2}\right)}{\mathrm{Dq}}
$$

From the experimental results one obtains:

$$
\begin{gathered}
\mathrm{X}=3.91 \\
\mathrm{~B}=82.74 \mathrm{meV}
\end{gathered}
$$

The Tanabe-Sugano diagram of Fig. 2 shows the dimensional values $(\mathrm{eV})$ of the ordinate scale because it has been drawn with the above value of $\mathrm{B}$.

The ${ }^{4} \mathrm{~T}_{2}$ transition directly gives the value of the crystal field strength for the $d^{3}$ system in octahedral symmetry. The values of the crystal field strength $\mathrm{Dq}$ and the Racaah parameter were calculated using the eqns. (1-3). Ilse and Hartman $^{22}$ have shown that for octahedral coordination $10 \mathrm{Dq} \approx\left(\frac{5 \mathrm{eq}}{3}\right) \frac{\left\langle\mathrm{r}^{4}\right\rangle}{\mathrm{R}^{5}}$ where $\mathrm{r}$ is the nucleus to electron distance, $\mathrm{R}$ is the ion-ligand distance, $\mathrm{e}$ is the electronic charge and $\mathrm{q}$ is the effective charge on the ligand. Changes during heat treatment can only affect the $\mathrm{Cr}-\mathrm{O}$ distance or the effective charge of the surrounding oxygen ions. The functional dependence of Dq on $\mathrm{R}$ and $\mathrm{q}$ indicates that changes in the $\mathrm{Cr}-\mathrm{O}$ distance should be 


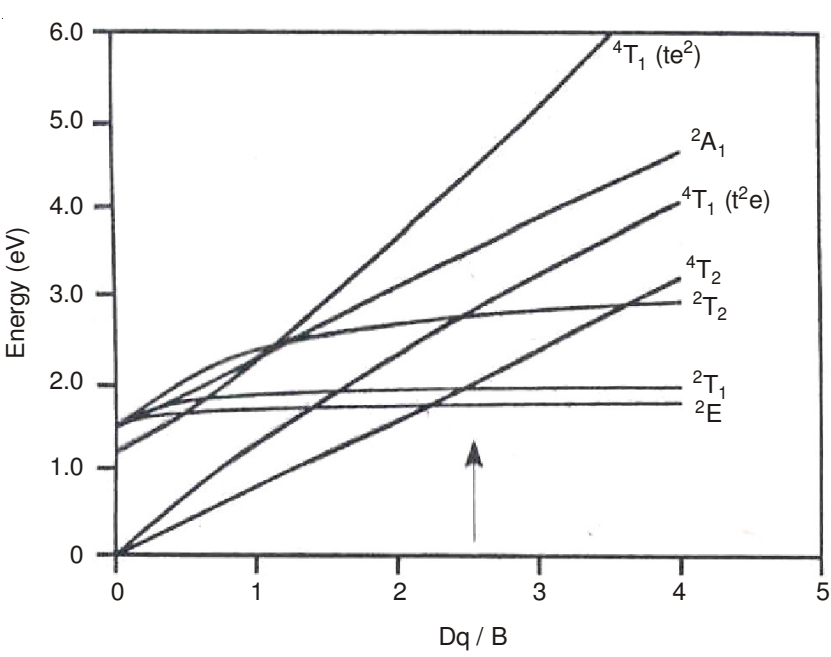

Fig. 2. $\mathrm{Cr}^{3+}$ levels in octahedral symmetry

more important than changes in the effective charge of the ligand. The effect of composition on the Racaah parameter B gives additional information on the nature of chromium sites. The reduction of $\mathrm{B}$ from its free ion value $918 \mathrm{~cm}^{-1}$ when the ion is placed in a matrix (solid) reflects the presence of some covalent bonding in the chromium complexes ${ }^{23}$.

Electron spin resonance analysis: The ESR measurements were reported for many Cr-doped systems ${ }^{4,24}$. Assignment of ESR spectra measured in glasses is sometimes rather complex. The ESR lines in glasses doped with $\mathrm{Cr}$ ions may be interpreted as resulting from $\mathrm{Cr}$ ions with different valencies as well as resulting from possible different resonance centers ${ }^{17}$. For example the vacancy centers accompanying the doped ions replacing non-equivalent atoms in the host material. The resonance line has a characteristic shape of ESR spectra measured for paramagnetic ions in crystalline fields with axial symmetry and with random orientations of their nearest polyhedra relative to external magnetic field (powder like) ${ }^{24}$. Effects on the dopant charge distribution, $\mathrm{Cr}^{3+}$, leads to distinct ESR spectra. The ESR spectra of $0.1 \mathrm{~mol} \%$ is shown in Fig. 3. The broad and sharp resonance signal appears at $\mathrm{g}_{\text {eff }}=1.97$ (Lande $\mathrm{g}$ factor), which are attributed to $\mathrm{Cr}^{3+}$ ions and $\mathrm{Cr}^{5+}$ ions ${ }^{4}$. Sharp signals observed at $\mathrm{g}_{\text {eff }}=1.97$ confirmed the presence of $\mathrm{Cr}^{5+}$ ions in the system. Comparing the spectra for the gels and heat-treated specimens it can be concluded that the concentration of $\mathrm{Cr}^{5+}$ ions increased with increase in heat treatment temperature. In the gel, only the signal due to $\mathrm{Cr}^{3+}$ is observed, which is in agreement with the optical absorption measurements. In contrast the sharp peak due to $\mathrm{Cr}^{5+}$ ions is dominant when the specimens were heat treated at higher temperatures.

Nature of $\mathrm{Cr}$ valence states in silica gel glass: The oxidation state of chromium in sol-gel glasses as well as its coordination number is controversial. Dependencies on the heat treatment temperature and the final $\mathrm{pH}$ value of the chromium ions could be incorporated as $\mathrm{Cr}^{3+}, \mathrm{Cr}^{5+}$ and $\mathrm{Cr}^{6+}$ in gel matrix ${ }^{10}$. With increasing temperature the conversion of $\mathrm{Cr}^{3+} \rightarrow \mathrm{Cr}^{6+}$ is promoted. On the other hand the increase of the $\mathrm{pH}$ value causes an increase of $\mathrm{Cr}^{5+}$ content. Other studies have postulated existence chromium in the sol-gel glass at 4+ oxidation state ${ }^{7}$. The experimental conditions applied in our synthesis should lead to the formation of the chromium ions
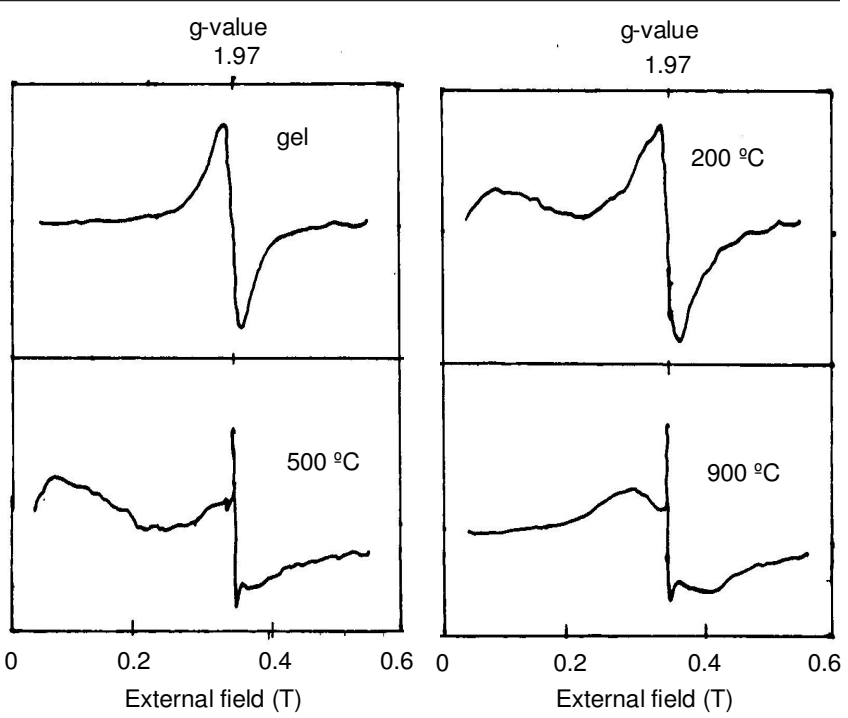

Fig. 3. ESR spectrum of the $0.1 \mathrm{~mol} \%$ gel and heat-treated specimens

at the highest oxidation states in spite of the fact that the starting substances contain the $\mathrm{Cr}_{2} \mathrm{O}_{3}$ oxide. The obtained $\mathrm{Cr}$-doped silica gel exhibits the absorption spectrum consisting of a structureless diffusive contour in the range 400-700 nm. The shape of this spectrum does not resemble that for typical $\mathrm{Cr}^{3+}$ doped glass. The crucial role in the doped silica gel glass is played by the charge compensation effect on the rule of the radius ratios $\rho_{\mathrm{e}}=\mathrm{r}_{\mathrm{H}} / \mathrm{r}_{0}$, the effective ionic radius extracted from Shannon's original work ${ }^{25}$. The effective ionic radius $\mathrm{r}_{\mathrm{e}}$ of $\mathrm{Cr}^{6+}$ in four-fold coordination is $0.26 \AA$ being the same as for $\mathrm{SiO}^{4+}$ $(0.26 \AA)$. Therefore the substitution of the $\mathrm{Si}^{4+}$ in tetrahedral site by $\mathrm{Cr}^{6+}$ is highly favourable even in the high covalency of $\mathrm{Cr}(\mathrm{VI})-\mathrm{O}$ bonds. In such a case the charge compensation of the $\mathrm{CrO}_{4}{ }^{2-}$ situated at $\mathrm{SiO}_{4}{ }^{4-}$ site is realized intrinsically by the formation of $\mathrm{Si}$ vacancies. One $\mathrm{Si}$ vacancy can compensate two $\mathrm{Cr}^{6+}$ ions due to the four-fold valency. Therefore half of the $\mathrm{Cr}^{6+}$ centers is compensated by the adjacent valency and the other half is compensated non-locally, giving the remaining electrons also to the Si vacancy complex and to the $\mathrm{Cr}^{6+}-\mathrm{Cr}^{5+}$ center.

The $\mathrm{r}_{\mathrm{e}}\left(\mathrm{Cr}^{5+}\right)$ in four fold coordination is $0.345 \AA$ and it is much larger than that one corresponding to $\mathrm{Si}^{4+}(0.26 \AA)$. A similar situation takes place when the effective ionic radii for these ions in six-coordination polyhedrons are compared. $\mathrm{r}_{\mathrm{e}}\left(\mathrm{Cr}^{5+}\right)_{\mathrm{CN}=6}=0.49 \AA$ and $\mathrm{r}_{\mathrm{e}}\left(\mathrm{Si}^{4+}\right)_{\mathrm{CN}=6}=0.40 \AA$. Therefore both these substitutions of the $\mathrm{Cr}^{5+}$ into tetrahedral and octahedral gaps are equally probable. The substitution of the $\mathrm{Si}(\mathrm{IV})$ in tetrahedral sites by $\mathrm{Al}(\mathrm{III})\left(\mathrm{r}_{\mathrm{e}}=0.39 \AA\right), \mathrm{Fe}(0.49 \AA) \mathrm{Ge}(\mathrm{IV})$ $(0.39 \AA)$ and $\mathrm{Cr}(\mathrm{IV})(0.41 \AA)$ is well known in silicates. The relative stability of $\mathrm{Cr}^{5+}$ at the tetrahedral site as compared to those at the octahedral ones could be due to the higher covalency of the $\mathrm{Cr}(\mathrm{V})-\mathrm{O}$ bonds in tetrahedral coordination ${ }^{24}$.

\section{Conclusion}

Porous sol gel matrices containing $\mathrm{Cr}^{3+}$ were prepared by sol-gel process. Controlled heat treatment were given to the prepared samples for densification. With increase in heat treatment temperature higher oxidation states of chromium were formed. The fresh silica-gel samples dried at $60{ }^{\circ} \mathrm{C}$ contain some amount of $\mathrm{Cr}^{3+}$. Heat-treated samples obtained under 
oxidative condition do not exhibit the presence of the $\mathrm{Cr}^{3+}$ ions in the absorption as well as ESR spectra. The presence of the $\mathrm{Cr}^{3+}$ ions in the fresh samples is allowed because of the $\mathrm{OH}^{-}$ions present in the silica gel. Heating at higher temperature shifts chromium ion to the higher valence states and a progressive disappearance of the $\mathrm{Cr}^{3+}$. The rule of radius supports the existence of highest oxidation states of chromium in the heat treated matrices.

\section{ACKNOWLEDGEMENTS}

One of the authors, Vinay Thomas is thankful to Univeristy Grants Commission (Government of India) for financial assistance.

\section{REFERENCES}

1. P.V. Jyothy, P.R. Reji Kumar, T. Vinoy, S. Kartika and N.V. Unnikrishnan, Pramana, 75, 999 (2010)

2. L.C. Klein, Sol-Gel Optics: Processing and Applications, Kluwer Academic Publishers, Boston (1994).

3. S. Roy and D. Ganguli, J. Non-Cryst. Solids, 195, 38 (1996).

4. K. Tanaka and K. Kamiya, J. Mater. Sci. Lett., 10, 1095 (1991).

5. M.J. Weber, J. Non-Cryst. Solids, 123, 208 (1990).

6. E.J.A. Pope and J.D. Mackenzie, J. Non-Cryst. Solids, 106, 236 (1988).

7. A. A. Boiko, E.N. Poddenezhny, J. Legendziewicz, J. Sokolnicki, E. Lukowiak and W. Strek, J. Appl. Spectrosc., 62, 625 (1995).

8. A. A. Boiko, E.N. Poddenezhny, E. Lukowiak, W. Strek, J. Sokolnicki and J. Legendziewicz, J. Appl. Spectrosc., 62, 629 (1995).
9. W.A. Weyl, Coloured Glasses, Scholar Press Ltd., Yorkshire (1978).

10. Y.X. Zhuang, M.J. Guan, J.H. Xie, Y. Teng, J.J. Zhou, S.F. Zhou and J. Ruan and J.R. Qiu, J. Phys. D: Appl. Phys., 43, 095401 (2010).

11. T.H. Maiman, Nature, 187, 493 (1960).

12. J.C. Walling, O.G. Peterson, H.P. Jenssen, R.C. Morris and E.W. O'nell, IEEE J. Quant. Electron., 16, 1302 (1980).

13. V. Petricevic, S.K. Gayen and R. R. Alfano, Appl. Phys. Lett., 53, 2590 (1988).

14. H. Eileves, W.M. Dennis, W.M. Yen, S. Kuck, K. Peterman, G. Huber and W. Jia, IEEE J. Qaunt. Electron., 29, 2508 (1993).

15. L.D. DeLoach, R.H. Page, G.D. Wilke, S.A. Payne and W.F. Krupke, OSA Proceed. Adv. Solid State Lasers, 24, 127 (1995).

16. R. Reisfeld and C.K. Jorgensen, Struct. Bond., 49, 1 (1982).

17. D. Shukla, L.K. Gupta and S. Chandra, Spectrochim. Acta A, 71, 746 (2008).

18. A. Pillonnet, C. Garapon, C. Champeaux, C. Bovier, H. Jaffrezic and J. Mugnier, J. Lumin., 87, 1087 (2000).

19. H.-H. Schmidkte, Struct. Bonding, 106, 19 (2004).

20. G. Fuxi, Optical and Spectroscopic Properties of Glass, Springer, Shanghai (1992).

21. M. Casalboni, A. Luci, U.M. Grassano, B.V. Mill and A.A. Kaminskii, Phys. Rev. B, 49, 3781 (1994).

22. F.E. Ilse and H. Hartmann, Z. Physik. Chem., 197, 239 (1951).

23. T. Bates, Modern Aspects of the Vitreous State, Butterworth, London (1962).

24. W. Strek, P.J. Deren, E. Lukowiak, J. Hanuza, H. Drulis, A. Bednarkiewicz and V. Gaishun, J. Non-Cryst. Solids, 288, 56 (2001).

25. R.D. Shannon, Acta. Crystallogr. A, 32, 751 (1976). 